\title{
O ESTUDANTE DE ENFERMAGEM E A SAÚDE DO TRABALHADOR - ESTUDO DE CASO DE UMA COLETIVIDADE DE MILITARES BOMBEIROS
}

Ieda Barreira e Castro* Suely de Souza Baptista**

\begin{abstract}
RESUMO - O estudo refere-se ao trabalho desenvolvido por professoras e estudantes da EEAN/UFRJ com 284 militares em um quartel do Corpo de Bombeiros da Cidade do Rio de Janeiro. Após a observação da ambiência e do exame simplificado de saúde dos militares, foi realizado o tratamento estatístico dos dados e eleaborado o diagnóstico simplificado de saúde, que baseou-se nos critérios de magnitude, transcedência e vulnerabilidade. As ações implementadas no campo de prática tiveram suporte teórico-prático. 0 número total de horas gastas com todas as atividades foi de 144 . 0 processo assistencial desenvolveu-se com uma perspectiva de aplicação do método científico e do compromisso profissional de contribuir para a melhoria da saúde da população.
\end{abstract}

ABSTRACT - This study was conducted by teachers and students from EEAN/UFRJ with 284 fire fighters in a fire house in Rio de Janeiro City. After the observation of the ambiance and of the simplified health exam of the fire fighters, the data was treated statistically, and a simplified health diagnostic was elaborated, based on the criteria of magnitude, transcendency and vulnerability. The implementing actions in the pratical field have been supported by theory and praxis. The total number of hours spent in all the activities was 144 hours. The assistance process was developed with a perspective of applying the scientific method and of the professional obligations in contributing to the improvement of the population health.

\section{INTRODUC̣ÃO}

Os programas dos três primeiros períodos do curso de graduação da Escola de Enfermagem Ana Néri / UFRJ são desenvolvidos paralelamente aos do ciclo préprofissional e seus cenários de prática são coletividades que congregam crianças, adolescentes e adultos ditos "sadios", isto é que não apresentam problemas de saúde capazes de impedí-los de desenvolver suas atividades.

As experiências de ensino-aprendizagem destes programas visam a: - oferecer precocemente ao estudante oportunidades de vivenciar situações relacionadas aos diferentes momentos do continuum saúdeenfermidade e seus condicionantes sociais e - iniciar o desenvolvimento de habilidades interativas, com indivíduos e grupos, a partir de um enfoque de autocui- dado. Além disso, o processo assistencial desenvolvese com uma perspectiva de aplicação do método científico e do compromisso profissional de contribuir para a melhoria da saúde da população.

0 programa curricular ora analisado é denominado "A Saúde das Pessoas que Trabalham" e é o terceiro de uma série de quinze que compōem o currículo do curso de graduação. Com ele se busca capacitar o estudante a analisar a inter-relação dos fatores físicos, psíquicos, sociais e ambientais da saúde do trabalhador; identificar as necessidades do trabalhador e o direito que tem à saúde e à assistência adequada; e tomar decisões com base no método de resolução de problemas. Esse programa desenvolveu-se no $1^{0}$ semestre letivo de 1986 e teve como cenário um quartel de Corpo de Bombeiros, onde tiveram experiências diversificadas de aprendizagem no que diz respeito às con-

* Professor Adjunto da Escola de Enfermagem Ana Neri. Universidade Federal do Rio de Janeiro

** Professor Titular da Escola de Enfermagem Ana Neri. Universidade Federal do Rio de Janeiro 
dições gerais de vida, às relações de trabalho e ao próprio processo de trabalho do bombeiro.

0 objeto do trabalho do bombeiro isto é, aquilo sobre o qual se aplica este trabalhador a fim de produzir, é principalmente of fogo. As situações em que atua são de alto risco, com perigo iminente de morte ou danos irreparáveis à saúde. Assim, tanto o bombeiro quanto as pessoas a quem se propõem ajudar vivem essas situações em estado de alta tensão emocional, sendo comuns as situações de pãnico. No intervalo entre uma e outra missão de socorro persiste a tensão, devido à expectativa permanente de um novo chamado, o que pode ocorrer a qualquer instante. Essas condições desfavoráveis que são inerentes ao trabalho do bombeiro são muito agravadas, no entanto, por outros fatores como veremos no decorrer deste trabalho. Como nos lembra PICALUGA (1983), "se é fácil detectar condições agressivas quando está presente algum agente físico, químico ou biológico, é verdade também que existem situações altamente agressivas devido a outras circunstãncias, e que estão intrinsecamente ligadas à exploração do trabalho".

A imagem social do bombeiro é a de uma pessoa forte, brava, destemida, um super-herói, porém, ao conhecer sua realidade um pouco mais de perto verificamos que eles enfrentam seu trabalho com tantos medos e dificuldades quanto qualquer um, mais, ainda, pelo próprio tipo de atividade que exercem e pelo modo como se dá sua inserção na instituição a que pertence.

Comparando-se a higidez dos 284 bombeiros examinados com o significado de saúde, na sua acepção mais simples, isto é "estado do indivíduo cujas funções orgãnicas, físicas e mentais se acham em situação normal" (Dicionário do Aurélio) podemos constatar que a maioria destes trabalhadores não se apresentam sadios. 0 mesmo dicionário apresenta ainda o vocábulo saúde como "força, robustez, vigor", palavras estas que se aplicam às condições necessárias à execução do trabalho desenvolvido pelo bombeiro.

As condições de saúde e trabalho do bombeiro, contrastam com o esforço que lhe é exigido, pois não existe relação satisfatória entre a situação de saúde deste trabalhador e as exigências de seu trabalho diário.

Neste contexto ocorreram as relações entre os estudantes de enfermàgem e essa corporação militar, mediante um processo de ajuda mútua em que os bombeiros receberam cuidados básicos de saúde e os estudantes receberam ensinamentos acerca de um saber inatingível pelos métodos convencionais de aprendizagem, pois decorre das vivências mesmas de uma parcela de nossa população trabalhadora.

0 presente estudo tem como objetivos:

Analisar um programa de saúde e as respectivas experiências de ensino-aprendizagem vivenciadas em um quartel do Corpo de Bombeiros.

Discutir a validade destas experiências do ponto de vista de ensino-aprendizagem e do ponto de vista assistencial.

\section{O PROGRAMA DE TRABALHO}

0 trabalho foi desenvolvido por três professoras, duas estudantes seniors do $8^{0}$ período e vinte e seis estudantes do $3^{\circ}$. período do curso de graduação em enfermagem da Escola Ana Neri/UFRJ com 284 militares em um quartel do Corpo de Bombeiros da cidade do Rio de Janeiro.

0 trabalho totalizou 144 horas, incluindo as experiências vivenciadas no campo de prática e as atividades teóricas e teórico-práticas que fundamentaram as ações práticas.

O desenvolvimento do programa inclui as seguintes frases:

\section{1. fase - Negociação da proposta de trabalho}

As professoras de enfermagem estabeleceram contato com a instituição a ser trabalhada, visando explicar a proposta de trabalho e verificar a existência de condições necessárias ao estágio como: locais para as entrevistas e para os exames de saúde, dias e horário das atividades, número de clientes a serem atendidos, etc.

Após preparar o treino simulado em sala de aula, foi realizada uma reunião dos estudantes e professoras de enfermagem com os dirigentes do quartel para apresentação, discussão e aprovação formal da proposta de trabalho. Esta atividade contou com a participação de todos os estudantes, sendo que um a coordenou, dois apresentaram a proposta e dois secretariaram. Depois dos esclarecimentos necessários a proposta foi aprovada.

$2^{\text {a }}$ fase - Diagnóstico da ambiência do trabalhador

A observação da ambiência do bombeiro no quartel onde trabalha foi realizada por quatro grupos de seis ou sete estudantes cada, acompanhados de uma professora de enfermagem e de um militar da corporação e gastou aproximadamente três horas. Cada um destes quatro grupos ficou responsável por alguns setores e utilizou um roteiro para orientar a coleta. A seguir os estudantes elaboraram relatório sobre as condições dos locais observados e foram levantadas as situações-problema.

3. fase - Entrevista. exame simplificado de saúde dos trabalhadores e intervenção de saúde individual

Nesta fase os estudantes usaram um roteiro para a entrevista e exame de saúde e um formulário para anotação das condições do cliente observadas pelo estudante e das mensurações feitas (peso e estatura, sinais vitais e acuidade visual e auditiva).

Cada estudante examinou em média dez militares bombeiros e gastou vinte horas para executar esta fase. Nesta etapa do processo de trabalho, além do exame, foram realizadas intervenções de saúde a nível individual, como orientações para o autocuidado acer- 
ca dos problemas identificados, encaminhamentos a outros profissionais, curativos, imobilizações, etc.

4. fase - Diagnóstico simplificado de saúde coletivo e Elaboração do plano global de intervenção

Ao término dos exames, os dados coletados foram tabulados, apresentando a distribuição de frequências absoluta e relativa. 0 diagnóstico simplificado de saúde foi elaborado a partir do relatório da observação da ambiência, dos resultados dos exames de saúde e do conhecimento dos recursos para resolução dos problemas e será apresentado no próximo capítulo.

0 estabelecimento de prioridades baseou-se nos critérios de magnitude - proporção da população afetada ou que poderá vir a ser afetada por um determinado problema; transcendência - impacto produzido e gravidade atribuída ao problema pela coletividade; e vulnerabilidade - tecnologia existente e disponível para a solução do problema. Para fins didáticos consideramos que esses critérios comportariam apenas três graus: alto, médio e baixo, aos quais seriam atribuídos 3,2 e 1 pontos respectivamente. Assim um problema de prioridade máxima obteria um total de nove pontos.

De acordo com cada problema ou conjunto de problemas da mesma ordem, determinou-se a natureza da ação requerida: se assistencial, educacional, administrativa ou de pesquisa.

5 a fase - Intervenção de saúde grupal e Avaliação

Optou-se pelos grupos de discussão, compostos de clientes, de estudantes e de professoras para aprofundar a discussão dos problemas detectados e tentar encontrar alternativas para solucioná-los, juntamente com os trabalhadores. Além dos problemas gerais foram também tratados os problemas dos clientes que assim o desejaram. Ainda nesta oportunidade, foi realizada a avaliação da ajuda prestada pelos estudantes de enfermagem àquela coletividade, através de um questionário distribuído entre os militares examinados que compareceram à reunião.

$6^{\text {a }}$ fase - Apresentação dos resultados do trabalho aos dirigentes da instituição

Apresentação dos resultados do trabalho desenvolvido aconteceu em uma segunda reunião geral dos estudantes e prof essoras de enfermagem com os dirigentes da corporação. Um estudante coordenou a reunião, dois apresentaram o diagnóstico simplificado de saúde da coletividade examinada e dois secretariaram a reunião.

Para cada situação encontrada foram apresentadas alternativas de solução.

7. fase - Avaliação do programa pelos estudantes de enfermagem

Esta avaliação foi registrada em uma dissertação sobre a atuação do estudante de enfermagem no campo de prática.

\section{O DIAGNÓSTICO DE SAÚDE COLETIVO E AS PROVIDÊNCIAS NECESSÁRIAS}

- Perfil do grupo examinado: o bombeiro.

Vale notar que os 284 indivíduos examinados representam apenas cerca de $15 \%$ da população que integra a coletividade. A seleção dos clientes foi feita pelos dirigentes do quartel, segundo sua conveniência, de modo que os resultados aqui apresentados se originam de uma amostra que pode não ser representativa do todo. No entanto permitem uma visão sintética do grupo trabalhado e dos problemas encontrados.

O grupo é composto totalmente de militares do sexo masculino: $70 \%$ de soldados, $15 \%$ de cabos, $12 \%$ de sargentos e $2 \%$ de oficiais. Esta população é relativamente jovem: cerca de dois terços de seus componentes têm menos de 35 anos; nọ entanto, encontramos indivíduos de até 55 anos. Quase a metade desses homens têm mulher e 1 ou 2 filhos. Os solteiros não chegam a um quarto e destes $80 \%$ declararam não ter filhos.

Metade dos soldados e cabos têm o $1^{\circ}$. grau completo, sendo que $30 \%$ dos soldados e $40 \%$ dos cabos têm o $2^{\circ}$. grau completo. Os sargentos dividem-se em igual proporção entre o $1^{\circ}$ e e $02^{\circ}$. graus. Nota-se não haver um programa de educação continuada, pois menos de $3 \%$ do grupo estuda: 1 soldado e 1 sargento estão cursando 02. grau enquanto que 5 soldados e 1 sargento cursam o $3^{\circ}$ grau.

Os soldados, cabos e sargentos percebem de dois a três salários mínimos.

- A ambiência do quartel.

A arquitetura do quartel é característica da passagem do século, com ampla utilização do ferro fundido, de sua natureza (quartel militar) e caráter (de bombeiros). Consta de um grande pátio circundado de prédios de dois andares. $\mathrm{O}$ acesso ao segundo andar é feito por escadas externas que vão dar em varandas que o contornam completamente. Nesses prédios se distribuem: os escritórios, auditórios e salas de música (banda militar), refeitórios, cozinhas e despensas; alojamentos e banheiros, áreas de lazer, consultório médico e de serviço social. Há uma torre de comando, de onde se exerce uma vigilãncia permanente sobre as varandas e o pátio. Do lado oposto à torre de comando há uma torre para a simulação de incêndios e salvamentos. 0 pátio é o cenário de todas as manif estações simbólicas coletivas da corporação e onde se faz "o adestramento físico no espaço da ordem", de modo a transformar os homens em uma força de trabalho disciplinada. As oficinas se localizam ao fundo do terreno.

Nota-se uma nítida classificação e especialização no uso do espaço: of iciais superiores; capitães e tenentes; subtenentes e sargentos; cabos e soldados; e burocratas - têm seus territórios demarcados, no que se refere aos refeitórios (com as respectivas cozinhas e 
despensas), área de lazer, banheiros e alojamentos. A densidade populacional, o grau de conforto proporcionado pelas instalações, sua conservação e limpeza e a qualidade da alimentação são diretamente proporcionais à posição dos usuários na hierarquia da instituição. Assim a grande maioria da população do quartel (soldados, cabos e sargentos) encontra-se mal servida em relação às instalações que lhes são destinadas, pois as mesmas não apresentam condições mínimas de higiene, segurança e conforto. A queixa sobre a qualidade das refeições é geral entre os praças, devido à precária conservação dos gêneros alimentícios - muitos até estragados - e ao preparo inadequado - alimentos mal cozidos, sem tempêro e com elementos estranhos. As reformas que se fazem mais urgentes são no abrigo dos socorristas (bombeiros de plantão), nas oficinas, no serviço médico e na cozinha e despensa dos cabos e soldados e na cozinha dos of iciais e suboficiais. Os reparos são urgentes nos sanitários e duchas dos soldados e cabos, nos cassinos de soldados e cabos e no dos sargentos. O alojamento dos burocratas não contam com banheiro. Bebedouros devem ser adquiridos e instalados, bem como um calibrador de pneus para a oficina mecânica. Essas medidas foram consideradas de alta prioridade (de 7 a 9 pontos), exceto as providências relativas ao banheiro dos burocratas, que foi considerada de média prioridade (6 pontos). As providências recomendadas são de ordem administrativa.

Uma outra ordem de problemas é a da higiene dos banheiros de cabos e soldados (que suportam cerca de 10(0) usuários por dia), das mantas e travesseiros de seu alojamento, bem como do abrigo dos socorristas (que há meses não são lavados). Provavelmente em decorrência do mal estado dos banheiros, notou-se também uma deficiência na higiene das mãos da grande maioria dos militares examinados. A limpeza dos banheiros e da roupa de cama foi considerada de alta prioridade e a lavagem das mãos, uma consequência dessa. Enquanto aqueles problemas requerem providências apenas administrativas, considerou-se que esse último requer também uma ação educativa, que favoreça a formação ou reforço do hábito. A má higiene da pele e das roupas de cama provavelmente concorre para a alta incidência de dermatoses, a que foi atribuída prioridade média ( 6 pontos) e que requer assistência médica, além da correção dos problemas de higiene acima indicados.

\section{- Os riscos ocupacionais.}

No que se refere às medidas de proteção e defesa contra os riscos ocupacionais, foram levantados dois problemas: um a falta de vacinação contra o tétano, da maioria dos bombeiros (mais da metade necessita das três doses), o que, considerando-se ser um grupo de alto risco, só não obteve prioridade máxima devido à dificuldade atual de obtenção da vacina; o outro, a deficiência, em quantidade e qualitlade dos equipa- mentos de uso individual de quem dispõem são o cinto, o capacete e as botas. Os demais (capas, luvas, máscaras, etc.) são de uso coletivo e sempre em número insuficiente para os usuários. Verbalizaram também que a maioria dos equipamentos de proteção são desconfortáveis e de eficácia contestável. A esses problemas foram atribuídas altas prioridades ( 8 e 7 pontos). 0 problema de deficiências visuais, constatadas em cerca de metade dos examinados, agravam o risco de acidentes, obteve prioridade média ( 6 pontos), devido às dificuldades de encaminhamento ao of talmologista e porque muitos bombeiros declararam não gostar de usar óculos. Mais do que o uso de óculos de grau os bombeiros valorizaram o uso de equipamentos de proteção contra a fumaça.

Outro problema detectado foi a falta de segurança no trabalho desenvolvido nas oficinas, principalmente devido ao pequeno espaço para a realização das atividades, a precária iluminação do ambiente e à falta de equipamentos de proteção.

Cerca de um terço dos bombeiros que responderam ao questionário declarou já haver sofrido um ou mais acidentes de trabalho, sendo que mais da metade desses acidentes ocorreu há menos de cinco anos. Mais da metade deles ocorreu fora dos cenários onde se dá o socorro, isto é, no próprio quartel (em atividades de treinamento simulado como salto de paraquedas, excesso de carga, etc., durante os exercícios de instrução física, nas oficinas, ao correr para atender ao brado da corneta) ou durante o transporte ao local do sinistro (acidentes de trãnsito, queda do veículo em movimento). No total dos acidentes sobressaem as quedas e pancadas (44\% dos casos declarados) tendo como consequência, cortes, contusões e fraturas. Os locais mais atingidos são as costas, principalmente em relação às quedas, e as mãos, principalmente em relação aos cortes e outros ferimentos. Surpreendentemente foram relatados apenas dois casos de queimaduras e nenhum de intoxicação por inalação de fumaça. Ao contrário, quando indagamos que equipamentos de proteção individual seria mais importante providenciar, as máscaras e as roupas contra fogo foram as mais mencionadas. Cabe aqui uma indagação saber se o conceito que têm os bombeiros de acidente de trabalho não inclui aqueles danos que não os obrigam a tirar licença de saúde. Igualmente solicitadas foram as cordas e os cintos. Outros equipamentos mencionados foram luvas, capacete, coturno, uniformes mais resistentes, capas de borracha, molas e travas, mangueiras e extintores, lanternas, machadinhas, rádio, cadeira, material de sapa, etc. Também foram solicitados materiais de primeiros socorros, tendo sido citados especificamente máscaras de oxigênio, inaladores e outros aparelhos. A grande maioria dos bombeiros enfatizou o problema da quantidade, da qualidade e da manutenção dos equipamentos, incluindo a falta de segurança of erecida pelas viaturas. 
- Os problemas de saúde.

O problema do "stress" atinge praticamente todos os militares examinados, em maiorintensidade e de modo mais ou menos permanente. Mais da metade declarou vir se sentindo tenso ultimamente, sendo que um quarto destes sente-se "muito tenso". Isto ajuda a explicar alguns dos sintomas relatados pela clientela como: problemas gastro-intestinais (mau hálito, língua saburrosa, azia, constipação, diarréia), dores de cabeça e tonteiras, obesidade e hipertensão, alterações do sono, excesso de álcool e de fumo, caspa, seborréia, queda de cabelo, onicofagia, transpiração excessiva, tremores e tiques nervosos. Outros problemas individuais encontrados também estão relacionados ao "stress" como alergias, herpes, dores nas costas, problemas renais e urogenitais. Ao "stress" foi atribuída alta prioridade (7 pontos), só não obtendo a cotação máxima devido à sua baixa vulnerabilidade. 0 grupo que apresentou excesso de peso (a maioria dos examinados) e/ou hipertensos inclui grande parte dos examinados, obtendo por si só alta prioridade (8 pontos). Para o "stress" foram indicadas ações educativas, administrativas (relacionadas às condições de trabalho e lazer) e de pesquisa (do tipo exploratório). Os hipertensos e/ou obesos necessitam além disso de assistência médica.

Outro problema detectado entre a quase totalidade dos examinados e que é comum à população brasileira é o da saúde bucal, principalmente no que se refere a dentes cariados e perdidos. Este problema comportaria uma ação educativa, além da assistência dentária, sendo no entanto de baixa vulnerabilidade na situação atual do nosso sistema de saúde.

Um terço dos examinados apresentou peso abaixo do normal, o que pode estar relacionado ao problema do tabagismo, aos problemas alimentares, ao próprio stress e a dificuldades de mastigação.

\section{AVALIAC̣ÃO DA AJUDA PRESTADA}

Consideramos como fontes de informação para esta avaliação as dissertações dos estudantes sobre sua atuação no campo de prática e o questionário respondido pelos bombeiros examinados, sobre a atuação do estudante de enfermagem. Um dos tópicos das avaliações tanto do estudante quanto do bombeiro, estava relacionado com suas opiniões sobre a utilidade do exame de saúde e da reunião de grupo, para os clientes individualmente e para a coletividade trabalhada.

Os estudantes consideraram que o exame de saúde e a reunião de grupo foram de muita utilidade para os clientes. Opiniōes coincidentes encontramos nos depoimentos dos bombeiros. Por um lado porque são pessoas carentes, não têm muitas oportunidades de conversar sobre seus problemas e fazer reclamações. No que se refere ao grau de liberdade existente durante a entrevista, $86 \%$ dos bombeiros declararam ter podido falar de seus problemas de modo "completamen- te" livre, enquanto que $13 \%$ sentiram-se "um pouco" livres para tal. Apenas um bombeiro achou que não teve oportunidade de se expressar.

Os depoimentos dos estudantes sobre a situação são os que se seguem:

"às vezes eu sentia que de repente eles (os bombeiros) viam na gente um meio de pedir ajuda, dizendo tudo que eles tinham vontade de dizer aos oficiais e não podiam, talvez na esperança de que pudéssemos modificar tal sistema."

"Vários de meus clientes chegaram a me dizer que era ótimo estarmos ali, pois durante aquele tempo em que estavam na entrevista eles poderiam relaxar e conversar com alguém, coisa que normalmente eles não conseguem fazer e também saber (como estava seu estado de saúde."

"Inclusive eles contaram para mim problemas não só de trabalho, mas também problemas familiares e sociais."

"na reunião eles compareceram quase que todos e deram depoimentos e sugestões.'

"tivemos oportunidade de fazer com que eles discutissem os problemas do grupo, tentanto uma interação maior de uns com os outros e em relação aos seus problemas."

Os depoimentos dos bombeiros são os seguintes: “"continuar de jeito que estão trabalhando, dandonos liberdade para falar tudo que sentimos, esclarecendo sempre qualquer dúvida que por ventura surgir."

"o trabalho foi muito bem aplicado pelos enfermeiros e nós pudemos e tivemos a oportunidade de contar nossos problemas com mais franqueza e principalmente sem nenhum receio."

Outro motivo alegado pelos estudantes e pelos bombeiros é o fato de os clientes terem oport unidade de tratar de seus problemas de saúde com pessoas capazes de ajudá-los a resolver essas situações, principalmente no que se refere ao reconhecimento de alguns condicionantes do processo saúde/enfermidade e à valorização do autocuidado.

Quanto a isto os estudantes se expressaram assim: "o exame de saúde é muito importante para o trabalhador pois através dele o cliente lembra de mínimas coisas que passam despercebidas por ele, mas que podem ser muito importantes."

“a utilidade do exame está na descoberta de pequenos problemas que podem agravar-se e na orientação quanto aoautocuidado, prevenindo ou controlando problemas que muitas vezes não são conhecidos."

"tentei salientar a importãncia do autocuidado, mostrando a eles o quanto é importante a luta por melhores condições de vida..." 
"na reunião de grupo o cliente tem mais uma chance de expor seus problemas e o estudante de enfermagem...poderá explicar coisas que o outro colega esqueceu na entrevista e questionar se foi válido ou não o seu trabalho.'

' durante a intervenção grupal que podemos observar se o nosso trabalho está obtendo algum resultado... e é um dia a mais que eles têm para tirar todas as dúvidas e para receber seus encaminhamentos."

Dos bombeiros examinados, $95 \%$ julgou o exame de "muita utilidade"; 4\% o achou de "pouca utilidade" sendo que um registrou a observação de "boa intenção e pouca utilidade" e dois não acharam utilidade alguma, sendo que um justificou: " não irá chegar ao conhecimento dos nossos comandados."

Outros depoimentos dos bombeiros sobre o assunto: "o trabalho foi otimamente desenvolvido. Pareceume boa interação, essencial em tal atividade. Foi bastante elucidativo saber da necessidade de imunização antitetânica de que nunca ouvira falar."

"valeu muito porque eu fui bem atendido. Eu estava com um problema, este problema for solucionado.'

Os estudantes e os bombeiros constataram que a utilidade deste tipo de trabalho para a coletividade está relacionada com a oportunidade de conscientizá-los so bre problemas de saúde.

Depoimentos dos estudantes:

“em relação à coletividade a importância está no esclarecimento a toda a coletividade de suas condições de saúde, evitando o agravamento de situações e a transmissão de doenças.'

"são pessoas supostamente sadias, que trabalham todos os dias, mas que têm suas queixas."

Depoimentos dos bombeiros:

' acho pouca coisa para melhorar pois nunca tivemos alguém para nos orientar sobre nossa saúde.'

Na percepção de um terço dos bombeiros respondentes ao questionário de avaliação da atuação do estudante de enfermagem durante o seu exame simplificado os estudantes não encontraram problemas de saúde algum. Os principais problemas detectados foram as deficiências visuais e os problemas dentários, mencionados por cerca de $25 \%$ dos bombeiros que responderam à questão. A hipertensão arterial e a tensão nervosa foram citadas por cerca de $20 \%$ deles.

Depoimentos dos estudantes:

"alguns bombeiros apresentaram hipotensão. Perguntei-lhes se haviam tomado o café da manhã, se dormiram bem, etc. Respondiam que ou não dormiam durante a noite ou que tinham se alimenta- do pouco. Outros bombeiros apresentaram hipertensão e estes diziam que estavam tensos e preocupados com problemas pessoais."

"considerei o problema da tensão o mais importante, devido ao ambiente de eterna vigília do quartel e as longas horas de trabalho dos bombeiros. A esse ambiente podem ser relacionados problemas como sono agitado, hipertensão arterial, tensão. (emocional).

' 0 ambiente tenso de trabalho e $o$ forte regime disciplinar contribuíram e muito para o alto índice de tensão entre os clientes.'

'clientes com sono agitado (devido), à jornada de trabalho que eles enfrentam e também por ser o serviço de bombeiro muito tenso, sempre com uma expectativa de ser chamado para apagar o fogo.'

Em relação às orientações recebidas pelos estudantes, $57 \%$ dos bombeiros mencionou-as de modo vago: "todas as necessárias", "muito boas", "a orientação correta', etc., sem no entanto especificar em que consistiram. Dos que especificaram o tipo de orientação, metade se referiu a encaminhamentos ao médico (dos quais a maioria ao of talmologista) ou ao dentista. Outras orientações mencionadas foram relacionadas à alimentação ou a dietas, à continuação de tratamentos já iniciados, à execução de curativos e tratamentos locais, à necessidade de vacinação antitetânica, à necessidade de verificar a tensão arterial periodicamente, à importância do lazer como modo de aliviar a tensão, à higiene pessoal, além de explicações sobre o próprio exame.

Esse resultado é coerente com aqueles encontrados para a pergunta "Suas dúvidas e problemas foram esclarecidos?" em que $62 \%$ responderam que "totalmente", $32 \%$ "parcialmente". Apenas 5 bombeiros (3\%) não se julgaram esclarecidos, enquanto que 4 não responderam e 1 declarou não necessitar de esclarecimentos.

\section{AVALIAC̣ÃO DAS EXPERIÊNCIAS DE APRENDIZÁGEM}

Os depoimentos pessoais das professoras e estudantes que integraram esse programa de ensino são os de um profundo enriquecimento pessoal. Em seus testemunhos ressaltam a importância das oportunidades de integração dos aspectos assistenciais e educacionais e de valorização da interação profissional, onde as pessoas são consideradas em sua totalidade. Destacam também as oportunidades de divulgação da enfermagem como profissão.

Os depoimentos constantes deste tópicos fazem parte da avaliação descrita (dissertação) dos estudantes, no que se refere às suas atuações no campo de prática.

Nesta avaliação os estudantes consideraram de muita utilidade para eles próprios o exame de saúde e a reunião grupal, pois tiveram oportunidade de co- 
locar em prática e aprofundar seus conhecimentos científicos, de relacionarem-se profissionalmente com as pessoas, de avaliar sua capacidade de trabalho, etc.

O Exame de Saúde:

"além da oportunidade de adquirir novos conhecimentos e aprimorar minhas técnicas, me proporcionou a chance de estabelecer contato com outras pessoas e problemas que não faziam até então parte de minha vida e de tentar buscar soluções para esses problemas... sem violentar as condições de vida de cada um, respeitando-as..."

"estimulou-se à aquisição de novos conhecimentos e informações a medida em que surgiam problemas novos para mim e que eu por não dominar ou desconhecer o assunto, recorria a pesquisas e conversas com quem pudesse me esclarecer."

"foi gratificante pois ajudou-me a adquirir conhecimentos em relação às condições físicas, psicológicas e sociais do trabalhador.'

"pude sentir na prática como está a saúde do homem trabalhador."

"pudemos ter um contato com aqueles homens e conhecer não só um pouco dos problemas deles como trabalhadores, mas também como chefes de família."

"tratamos uma clientela diferenciada, aduita, com inúmeros problemas e situações diversas, que nos foram apresentadas (pelos bombeiros) com esperança de resolução. Este relacinamento nos aproximou mais da realidade do trabalhador."

"teve um que se sentiu tão à vontade que até ensaiou "cantadinha", mas eu, mais do que nunca, procurei responder o mais profissional possível voltando a estabelecer o clima de profissionalismo e coleguismo que a meu ver não pode deixar de ter."

"para mim o exame foi muito importante pois adquiri mais experiência, principalmente por se tratar de uma clientela adulta."

\section{A Discussão Grupal:}

"pude me deparar com uma situação nova, onde perguntas que não foram programadas poderiam surgir e eu e meu grupo teríamos que respondêlas, sem uma preparação especial."

"na reunião de grupo tive oportunidade de expressar-me melhor diante do grupo, pois não tenho muita facilidade e achei que foi uma boa oportunidade para vencer este tipo de barreira."

"na reunião de grupo deve ser feita para uma troca de informações e para observarmos os resultados de nossas entrevistas."

Os depoimentos à seguir dizem respeito ao alcance dos objetivos do programa curricular como um todo, do ponto de vista do perfil do estudante ao término do ciclo pré-profissional. "através de exames e reuniões foi ficando cada vez mais claro para mim a relação dos fatores físicos, psíquicos e sociais, já que todos os bombeiros recebem pouco, trabalham muito, tendo sérios problemas psíquicos e este provocam alterações em seus organismos.'

"valeu muito nossa atuação no Corpo de Bombeiros... nós pudemos encontrar aí uma comunidade que apesar de ser supostamente sadia, apresentava diversos problemas."

"eu adquiri uma ótima experiência para a realização de trabalhos com metodologia científica."

"esse trabalho para mim, entre todos que realizei foi o mais gratificante. Trabalhar com adulto é olho no olho(...) as verdades são ditas claramente."

"o trabalho realizado marcou nossa passagem pelo ciclo pré-profissional. Acredito que tenhamos alcançado a maioria dos objetivos e competências assinalados, que nos serão úteis por toda a vida universitária e profissional."

"agora posso verificar que todos (os objetivos do estágio) foram alcançados e que pude melhorar meus conhecimentos e experiências, que valem muito mais que teorias."

Um outro tópico constante da avaliação referia-se às dificuldades e facilidades encontradas pelo estudante de enfermagem no campo de prática.

Quanto às facilidades encontradas, seus depoimentos referem-se ao respaldo científico e emocional of erecido pela equipe responsável pelo desenvolvimento do programa de ensino; a boa receptividade para com o trabalho por parte dos dirigentes da corporação e a participação do cliente durante a entrevista, como se segue:

"houve um maior entrosamento das professoras com os estudantes e dos estudantes entre si porque todos fazem parte de uma equipe."

“o grande número de clientes (examinados por nós) o que nos deu uma vasta oportunidade de experiências novas."

"os clientes foram muito gentis, mostraram boa vontade... e acreditaram no meu trabalho."

"as professoras e as seniors estavam sempre perto para esclarecer alguma dúvida e nos passando confiança sobre o nosso papel lá."

As dificuldades apontadas pelos estudantes têm estreita relação com a disciplina militar, com o fato de que o grupo de trabalho era composto quase totalmente por mulheres e com a precariedade dos serviços de saúde da corporação. Eles expressaram suas dificuldades assim:

"apesar de os militares não terem sido esclarecidos da intenção de uma nova reunião ou de terem sido tirados de suas folgas especialmente para isso." 
"foi difícil para nossa equipe, quase que totalmente composta de mulheres, agir em uma comunidade onde a população na sua totalidade é masculina."

"o barulho, o toque da corneta que às vezes chamava os clientes que estavam sendo entrevistados, falta de local para lavarmos as mãos."

"a dificuldade que me incomodou foi a falta de um local adequado para fazermos o teste de acuidade auditiva ou seja um local calmo e com cadeiras."

"a falta de vacina antitetânica, que seria um dos objetivos mais importantes do nosso trabalho."

\section{POSSIBILIDADE E CONVENIÊNCIA DA CON- TINUIDADE DO PROGRAMA}

A concepção elitista, característica das instituições militares, constitui-se em importante obstáculo ao desenvolvimento de um programa de Cuidados Básicos de Saúde.

Durante o estágio, a rigidez da disciplina militar se fez sentir em diversas ocasiões:

- inicialmente, quando o Chefe do Serviço Médico relutou em aceitar o trabalho, por considerar que os militares bombeiros têm assistência médica suficiente para atender aos seus problemas de saúde. No entanto, os depoimentos dos estudantes e dos bombeiros não são coincidentes com esta declaração oficial.

Dizem os estudantes:

"apesar de ficar angustiada por ver tantos problemas e ver a burocracia que é, quando se tem um problema de saúde, para se ter um atendimento digno."

"havia um descrétido muito grande dos bombeiros em relação a nós e aos nossos encaminhamentos. Diziam que não ia adiantar nada. Que eles de qualquer maneira não seriam atendidos."

“o único ponto que me questiono é o seguinte - será que os nossos clientes serão mesmo encaminhados(...)? De qualquer forma, mesmo com essa dúvida, acho que nossos esforços não foram em vão e os clientes aprenderam um pouco do que tínhamos a lhes ensinar."

Os bombeiros confirmam:

" na medida do possível, acompanhar de perto os casos que vocês recomendem tratamento médico (porque nem sempre nossos problemas são vistos pelos médicos ou pessoas que lidam com nossa saúde) ou problemas que carecem de cuidados especiais."

"que (o exame) seja feito juntamente, digo em conjunto com o pessoal médico da corporação."

Aquela rigidez continuou se fazendo sentir quando os dirigentes da corporação se sentiram autorizados a decidir sobre nossa proposta de trabalho sem a mínima participação dos interessados. Durante os exa- mes e as reuniões com os grupos, os bombeiros compareceram sem conhecer a finalidade de sua presença naquele local, explicando que estavam ali por ordem superior e que se faltassem poderiam ser presos: - ainda durante o exame, várias vezes ocorreu a retirada de clientes, para algum outro tipo de atividade: - outras vezes houve a impossibilidade de utilizar o local previamente acertado para a realização dos exames, devido a que um oficial requisitara o mesmo espaço. Estes fatos foram registrados pelos estudantes ao alinharem as dificuldades sentidas durante 0 estágio:

"outra dificuldade foi a barreira imposta por uma sociedade militar onde manda e desmanda o comandante e todos obedecem, por que é assim há anos, anos e anos."

"desinformação dos soldados quanto ao exame, dificuldade para liberação dos mesmos, interrupção da entrevista (para prática de instrução física), convocação indevida de militares não examinados para a intervenção grupal."

"outro fato que dificultou bastante foi o regime militar rigorozíssimo, que os obrigou a comparecer ao nosso local de trabalho sem saber porque."

" "perdemos um bom tempo... para tentar descontraí-los, já que eles foram à nossa procura sem saber para que e se sentindo como cobaias."

"logo no início um bombeiro pediu que a gente não voltasse mais, porque eles eram obrigados a serem nossos clientes, que atrapalhávamos seu serviço e seu horário de almoço. Ficamos estarrecidos com a sinceridade do bombeiro."

"a primeira pergunta que eles faziam era por que nós queríamos saber de todas as coisas que estavam no formulário e sempre eu tinha que responder sobre nosso trabalho, que é um exame simplificado de saúde, mas que eles poderiam ficar tranquilos que o exame não chegaria às mãos dos superiores e sim um relatório com dados estatísticos."

Algumas sugestões dos bombeiros para melhorar nosso trabalho no próximo semestre deixam entrever a barreira existente entre os comandantes e seus comandados:

"que seja optativo participar ou não desses exames e que seja mostrado o resultado desta 1 a avaliação."

"tentar uma reunião com os oficiais para tentar esclarecer que o seu relacionamento com os praças está totalmente errado."

"o poder de levar ao conhecimento das autoridades responsáveis todas as necessidades que temos dentro do Corpo de Bombeiros."

Outra ordem de fatores condicionantes dos problemas de saúde desta coletividade, são de difícil abordagem por prof essoras e estudantes, pois envolvem as condições gerais de vida, as relações de trabalho e o próprio processo de trabalho. 
Segundo PICALUGA (1983), as condições gerais de vida podem ser classificadas em dois grupos: - as propiciadas pelo padrão e volume dos bens de consumo coletivo: transportes, saneamento, urbanização, educação, assistência médica preventiva, atenção médica e medicamentos, of erecidos pelo Estado; - e as condições que incidem sobre os bens de consumo individualizado: alimentação, habitação, vestuário, lazer, obtidos pelo salário. Também nestes aspectos a situação da coletividade estudada é semelhante a das classes de mais baixa renda, onde se caracteriza uma insuficiência e inadequação tanto dos bens de consumo coletivo quanto dos bens de consumo individualizado. A maior parcela da população do quartel é constituída de soldados, cabos e sargentos. As precárias condições das instalações e da alimentação destinadas a esses praças, muito se assemelham às condições de moradia $\mathrm{e}$ alimentação da população mais pobre da cidade, que apresenta carências alimentares quantiqualitativas e vive em condições ambientais muito desfavoráveis: suas casas pequenas para o número de pessoas residentes, muitas não têm água encanada nem esgoto, são distantes do local de trabalho e não dispõem de área de lazer.

BOHADANA, et alii (1983) mostrando que muitas doenças estão mais relacionadas à precariedade das condições de saneamento básico e de habitação, do que à inexistência de serviços de saúde, destacam que a distribuição do saneamento coincide com a distribuição da renda, pois a população que reside em domicílios inadequados percebe menos que três salários mínimos.

Ao contrário, a precariedade da situação do quartel não depende do baixo poder aquisitivo dos bombeiros e sim de uma política de pessoal retrógrada. A alegação dos dirigentes, de que a culpa pelo mau estado das instalações sanitárias é dos próprios usuários, não resiste à crítica, pois não há como justificar a relação numérica instalações sanitárias/usuários. Um banheiro, com um mictório e cinco sanitários para uso de sessenta sargentos e subtenentes - o outro, com dois mictórios e dez sanitários para uso de 1000 soldados e cabos. Ocorre ainda que a limpeza destes banheiros é feita apenas uma vez por dia e não há programa de manutenção.

Esta situação interna tem como agravante os baixos salários percebidos. Os estudantes constataram a situação:

"as cáries dentárias foram muito freqüentes o que, ao meu ver, refletem o nível sócio-econômico dessa população, já que a faixa salarial é de Cz\$ $2.400,00$, provavelmente faltando para o orçamento doméstico, quanto mais para o serviço odontológico."

O salário insuficiente faz com que esses trabalhadores assumam outras atividades profissionais fora do quartel, durante o horário reservado para seu descan- so e lazer, visando a aumentar seus rendimentos e com isto poder atender suas necessidades básicas.

"tem algum problema que lhe causa maior preocupação? Quer falar sobre ele? A partir desta pergunta o cliente falou das condições de trabalho, dos serviços extras que têm que fazer para suprir a deficiência salarial, do péssimo atendimento médico dado ao soldado no hospital a que tem direito (...)."'

COSTA (1983) registra que "o cansaço produzido pelo ritmo intenso de trabalho, o grande número de horas trabalhadas por jornada, além da insuficiência de medidas preventivas que as empresas deixam de adotar, para não onerar os custos da produção, faz com que, seja bastante elevada a frequência de acidentes". No que se refere ao bombeiro, o deficiente esquema de prevenção de acidentes agrava desnecessariamente a questão do risco e do stress ao seu trabalho.

Pelo diagnóstico da coletividade constatamos um percentual significativo de pessoas que se declaram estressadas pela natureza do trabalho que desenvolvem. Relataram que, ao brado da corneta de "chamada geral dos bombeiros", ficam tensos e preocupados, antes mesmo de conhecerem a natureza da situação que irão enfrentar.

Todas essas carências explicam a incidência de muitos dos problemas que afetam a saúde da coletividade estudada.

Os estudantes perceberam estas situações do seguinte modo:

"tive a oportunidade de analisar alguns fatores que interferiam diretamente na saúde daqueles trabalhadores como falta de equipamentos de proteção individual (...), o ambiente de trabalho em condições precárias, atendimento médico sem higiene, sem conforto, alimentação ruim, tensão geral ocasionada por pressão (segundo depoimentos), salários baixos, insignificantes, o que provoca a procura de outros empregos (subempregos)."

"eu tinha a idéia de ser o bombeiro um super herói, sempre forte, pronto para qualquer situação e de repente acordei para uma realidade totalmente diferente e descobri que dentro de toda profissão existem preconceitos, injustiças, problemas de ordem política, econômica e coisa e tal."

Os próprios integrantes da coletividade estão conscientes das consequências desses problemas para a saúde:

“de minha parte eu estou muito satisfeito, mas que apareçam sempre com aquele carinho com que nos atenderam e não deixem de comparecer pois alguns colegas sofrem de outros males como a hipertensão coronária, doença de nervos e outros têm disrritmia cerebral, insônia, stress e vivem sob esgotamento físico e mental."

A precariedade dos serviços de saúde aos quais o bombeiro tem direito não pôde ser compensada devi- 
do à inexistência de convênios entre a Escola Ana Neri e outras instituições de saúde. 0 problema da má qualidade do atendimento médico-hospitalar foi bastante citado pelos examinados que resistem o quanto podem em procurar o hospital da corporação. Queixaram-se do longo tempo de espera para conseguir uma consulta e da qualidade destas consultas, inclusive pelo difícil relacionamento com os médicos, que são seus superiores hierárquicos. Cabe ressaltar que para afastarse do trabalho, o bombeiro só terá sua licença assegurada se for ao Hospital do Corpo de Bombeiros. Por outro lado, eles não têm condições financeiras para recorrer à assistência médica particular. Esta situação contribui para o reconhecimento tardio de doenças, quando o bombeiro já se sente incapaz para o trabalho, devido ao agravamento dos sintomas.

Os bombeiros trataram deste assunto, durante os exames de saúde e nas reuniões, de forma enfática, fazendo críticas e dando sugestões para a resolução do problema:

“no Corpo de Bombeiros é feito exame de 3 em 3 anos, até que se complete 10 anos (eles só fazem isso para ver se o bombeiro está em condições de permanecer na corporação). Depois de 10 anos (de serviço) não há um controle por parte deles."

"na minha opinião acho que deveria haver convênio(s) com hospitais e clínicas em diversos pontos do nosso Estado, pois o tratamento odontológico, por exemplo, é quase que nulo na nossa corporação. Existe apenas o nosso hospital, que além de mal localizado, distribui um número pequeno para esse tipo de tratamento e uma clínica em Campinho que oferece apenas quatro números para um contingente grande de bombeiros e um sem fim de dependentes."

"uma pequena sugestão - que fossem coletados materiais para exames (sangue, fezes, urina, etc.) pois no nosso hospital o número de bombeiros e dependentes é muito grande para um só posto de atendimento, enquanto a clínica de Campinho, na minha opinião, não deveria nem ter sido construída, pois não tem nada."

Os estudantes perceberam suas preocupações:

"todos, sem exceção, reclamaram da assistência hospitalar. Desacreditam do hospital..."

"seus depoimentos, verdadeiros desabafos, denunciaram desde as condições de higiene e trabalho até a precária assistência médica ao soldado e sua família."

Em relação aos problemas levantados, nossa contribuição ficou limitada à sua detecção, à comunicação dos mesmos aos dirigentes da instituição e à apresentação de alternativas de solução viáveis, pois não houve oportunidade para discussão e muito menos de participar da execução das medidas propostas. Apesar da aquiescência por parte do comando em relação à nossa proposta inicial de trabalho, após o diagnóstico não houve possibilidade de se discutir com os dirigentes alguns assuntos e tomar providências, no que se refere aos problemas de saáúde encontrados, condições de trabalho, de assistência médica, etc.

Porém um estudante percebeu alguns aspectos positivos na situação:

"boa recepção por parte das autoridades, com chances de visita às instalações do quartel e possibilidade de exposição de nossos dados estatísticos e conclusões finais."

No entanto houve o seguinte comentário de outro estudante:

"a possibilidade e a conveniência de prosseguir eu acho que é pouca, embora o comandante tenha afirmado que nós sempre seríamos bem recebidos."

Os bombeiros mostram-se um tanto pessimistas mas ao mesmo tempo esperançosos:

"encaminhar rigorosamente todos os dados fornecidos às autoridades médicas."

"conseguir junto ao Comando o cumprimento relativo à saúde dos militares."

"esse trabalho que foi feito, na minha opinião foi válido. Que seja levado a sério pelo nosso Comandante."

“em 1 ? lugar vocês terão (que ter) total apoio da corporação, caso contrário não vai adiantar nada. Espero que vocês voltem porque isto é bom para nós, desde que a corporação dê apoio a vocês neste trabalho útil para todos nós. Que estes exames não fiquem apenas no papel."

"procurar mais apoio para que esses exames não parem por aqui."

Ainda sobre a possibilidade e conveniência de prosseguir o trabalho neste campo de estágio, percebemos pelos depoimentos dos estudantes e dos bombeiros que a grande maioria considerou a experiência válida e que deve ser continuada. Os estudantes porque:

"a possibilidade de continuar o trabalho no próximo semestre eu acho que... é muito boa. Na última reunião nós recebemos o convite do subcomandante do quartel. Eles já nos conhecem e assim pode ficar mais fácil."

“acho extremamente válida a continuação do estágio no quartel... seria bom que os novos estudantes verificassem se realmente nosso trabalho gerou alguma mudança, pois é um trabalho a longo prazo."

"na reunião de intervenção grupal tivemos certeza dessa utilidade através de novos depoimentos e através dos formulários preenchidos, onde a maioria das sugestões falava sobre a continuidade do trabalho."

"a presença de civis, num quartel militar pode causar uma certa preocupação, por parte dos milita- 
res, que temem que carências e deficiências sejam expostas e transpostas para fora deste estabelecimento(...)pode ter sido até um desafio (para eles) abrir as portas do quartel para um grupo de civis, mas nós ocupamos lá nosso espaço."

No que se refere às sugestões para a melhoria de um próximo programa os bombeiros se manisfestaram do seguinte modo: cerca de um quarto deles enfatizaram a necessidade de acompanhamento das providências decorrentes do diagnóstico simplificado.

"o trabalho está ótimo, os problemas de saúde detectados. Precisamos agora sanar estes problemas."

"gostei dos exames, mas que as autoridades levem à sério e cuidem de seus materiais humanos."

"que seja divulgado nos órgãos competentes visando melhoras nos problemas encontrados e que 0 estágio continue com pleno êxito no próximo semestre e nos demais semestres vindouros."

Cerca de $10 \%$ sugeriram que fossem feitos exames simples de laboratório. Dois deram sugestões para a melhoria do ambiente de trabalho. Dois apresentaram sugestões relativas ao controle da hipertensão: verificações periódicas e antes da avaliação física. Apenas dois sentiram falta da vacina antitetânica. Um sugeriu a utilização de material mais resistente para o teste de acuidade visual.

Nem todos entenderam a proposta de Cuidados Básicos de Saúde: $10 \%$ sugeriu que o exame fosse "mais rigoroso", "mais aprofundado" ou "mais preciso". Exemplos de solicitações desse grupo são Raios X, eletrocardiograma, eletroencefalograma. Dois solicitaram tratamento dentário. Um sugeriu a presença de um médico da OMS (talvez porque sua experiência com os médicos nacionais não tenha sido muito positiva...)

A maneira inadequada como foi feita a convocação para o exame se reflete nas sugestões de que o mesmo seja opcional ou de que seja só para quem está entrando de serviço e não para quem está saindo de plantão. Um deles demonstrou sua rejeição ao programa como a seguinte sugestão: "não tentarem resolver nossos problemas e sim o de vocês". Outro sugeriu que o exame fosse estendido aos familiares. Mais da metade dos que apresentaram sugestões acha que o programa já está bom, não necessitando portanto de sugestões ou apenas sugeriram que o exame fosse repetido periodicamente:

"digamos que fosse feito periodicamente para que fosse acusado qualquer problema em qualquer tempo."

"seria de grande importãncia caso fosse trimestral, pois assim traz mais conhecimento para todos. Faz com que o indivíduo procure zelar pela sua saúde."

Embora o questionário não tratasse do assunto, vá- rios bombeiros se referiram às suas condições de trabalho, apontando a necessidade de um melhor relacionamento interpessoal ("melhor orientação no trabalho prático", "um crédito de confiança para o bombeiro", "liberdade" e "espírito de camaradagem").

Um grupo mais numeroso se referiu à necessidade de reduzir a jornada do plantão, que por direito deveria terminar às oito horas e não às onze horas; vale notar que esse (8 às 11) foi justamente o utilizado para o desenvolvimento dos nossos trabalhos; outros se referiram à importância do reconhecimento de outros direitos como melhores salários, assistência médica, segurança para a família e melhores condições de alojamento (roupas de cama, etc.).

No entanto por se tratar de uma comunidade militar parece não existir a possibilidade de o trabalhador tentar controlar a situação, impedidos que estão de organizar-se politicamente para reivindicar melhores condições de vida e trabalho.

A problemática de vida e trabalho, condicionante do estado de saúde das pessoas examinadas, é determinada pelas políticas governamentais. Considerando não se observar uma vontade política dos dirigentes da corporação de tentar minimizar os problemas internos do quartel e a impossibilidade de se manifestar a vontade do grupo - parece remota a probabilidade de que a situação apresentada venha a ser modificada, pelo menos a curto prazo.

A partir daí se pode começar a questionar a conveniência de se dar continuidade a um estágio que atende satisfatoriamente apenas ao que interessa ao desenvolvimento do processo ensino-aprendizagem, já que não há um prognóstico favorável da situação de saúde.

Coloca-se então um problema ético: o da validade de se detectar falhas, inspecionar o corpo das pessoas, ouvir-lhes os segredos, mobilizar suas esperanças, avivar seus anseios, sabendo-se de antemão que não os poderemos ajudar a resolver os problemas. Será suficiente consolá-los? Assim sugere o patético depoimento de um bombeiro:

"no mais, eu adorei o tratamento dispensado a nós e espero que sempre sejamos atendidos por pessoas assim dedicadas e interessadas em ajudar, mesmo que não tenha essa possibilidade, mas pelo menos demonstre..."

\section{BIBLIOGRAFIA}

1. BOHADANA, E. et alii. Condições de vida. In: IBASE, Saúde e trabalho no Brasil. 2. ed., Petrópolis, RJ, Vozes, 1983, p. 17-28.

2. COSTA, N.R. Acidentes de trabalho. In: IBASE, Saúde e trabaIho no Brasil. 2. ed., Petrópolis, RJ, Vozes, 1983, p. 29-34.

3. PICALUGA, I.F. Saúde e trabalho. In: IBASE, Saúde e trabalho no Brasil. 2. ed., Petrópolis, RJ, Vozes, 1983, p. 37-42. 